\title{
Survey on College English Follow-up Elective Courses (Section A)
}

\author{
Bin Chen \\ School of Foreign Languages \\ Wuhan Institute of Technology \\ Wuhan, Hubei province, China \\ E-mail: apple163@163.com
}

\author{
Yuanyuan Zhang \\ School of Foreign Languages \\ Wuhan Institute of Technology \\ Wuhan, Hubei province, China
}

\begin{abstract}
To meet non-English majors' English learning needs, College English Follow-up Elective Courses system was set up at our school, and ten English Elective Courses were provided for them to select according to their requirement for the first time. To probe students' feedback concerning College English Follow-up Elective Courses, The present authors adopted questionnaire to collect data, and made a descriptive analysis of the data. Based on the data analysis, discussion and suggestions were offered.
\end{abstract}

Keywords-College English Follow-up Elective Courses; students'feedback; survey; suggestions

\section{INTRODUCTION}

College English course system has changed a lot since College English Curriculum Requirements (2007edition) was implemented in 2007. Many colleges and universities have added College English Follow-up Elective Courses to their College English course systems. Based on abundant discussion and survey, for the first time, ten College English Follow-up Elective Courses were added to College English course system of our school for college non-English majors who were enrolled in September 2013. From March 1, 2015 to June 30, 2015, all college non-English majors who were enrolled in September 2013 took one of the ten College English Follow-up Elective Courses. In order to obtain information about students' feedback concerning College English Follow-up Elective Courses they took, the present authors made a survey among non-English majors who had taken the courses. It aimed to probe students' feedback regarding the existing type and number, textbook, teaching methods, assessment and learning effect of College English Follow-up Elective Courses, and to find out improvement measures for further development of College English Follow-up Elective Courses.

\section{LITERATURE REVIEW}

According to College English Curriculum Requirements (2007edition), College English course system is supposed to be a combination of required and selective courses in comprehensive English, language skills, English for practical uses, language and culture, and English of specialty[1]. Based on their purposes of fostering students, students' English levels and learning needs etc., College English course systems of many colleges and universities are composed of English for General Purpose and College English Follow-up Elective Courses. As for literature on College English Follow-up Elective Courses, There are many published papers about College English Follow-up Elective Courses designing[2][3]. Only a few papers inquire College English Follow-up Elective Courses teaching and learning. Wang (2011) Analyzes the market needs and the graduates' expectations for college English teaching and learning based on an investigation to social needs for College English [4]. Fu (2014) makes a questionnaire to get information about students' demands for follow-up English elective courses and their purposes of learning English among non-English majors who have passed CET4 or CET6 test [5]. Chen (2015a, 2015b) makes an experiment on Chinese culture teaching through College English teaching [6], then follows a survey and finds that $43.3 \%$ subjects wanted to learn Chinese culture in English systematically and fully, so she suggest considering Chinese Culture as one of the College English Follow-up Elective Courses for college sophomores[7]. There is not any published paper about students' feedback concerning College English Follow-up Elective Courses. So it is necessary to probe it, especially for colleges and universities which newly have College English Follow-up Elective Courses set up and carry out them for the first time.

\section{DESIGN AND Method}

\section{A. Subjects}

100 non-English majors, who took College English Follow-up Elective Courses from March 1, 2015 to June 30, 2015(a semester), were randomly chosen as subjects. They were college sophomores and enrolled in September, 2013. All of them were Chinese coming from different provinces of China. Their average age was 19 years old. The subjects consisted of $60(60 \%)$ males and $40(40 \%)$ females. And before the survey, they had studied College English Followup Elective Courses for a semester (From March 1, 2015 to June 30, 2015).

\section{B. Instrument}

The instrument of the present study was a 10-item questionnaire, which was designed by the present author. 
The questionnaire consisted of one open-ended question and nine closed questions that required subjects to choose one from the multiple answers.

\section{Research Procedure}

After the subjects took College English Follow-up Elective Courses for a semester (from March 1, 2015 to June $30,2015)$, the present author handed out the questionnaires to the subjects. In order to get rid of their confusion, the present author instructed the subjects how to fill out the questionnaires. They were asked to fill out the questionnaires within 15 minutes in class. After they finished the questionnaires, the present author collected questionnaire in time. Then the present author made the census of the collected questionnaires and the descriptive analysis of the data. Based on the result of data analysis, discussion and suggestions were offered.

\section{RESULTS AND DISCUSSION}

100 Questionnaires were distributed to the subjects, and 100 returned Questionnaires were valid ones. Results of the data analysis and discussion on the results are as follows:

As for the existing type of College English Follow-up Elective Courses, $52 \%$ subject viewed that they were limited, $45 \%$ subjects viewed them reasonable. About their idea type of College English Follow-up Elective Courses, 18\% subject hoped to choose Chinese or western culture courses, 37\% subject hoped to choose English for cultural recreation use like English for Tourists, $22 \%$ subject hoped to choose Oral English, 7\% subject hoped to choose English for tests like CET-6, 8\% subject hoped to choose English for Academic Purposes, and $8 \%$ subject hoped to choose English for employment or vocations use. These results showed that the type of College English Follow-up Elective Courses was not abundant enough to meet students' need. The type of College English Follow-up Elective Courses in future ought to be expanded.

Considering the existing number of College English Follow-up Elective Courses, 52\% subject viewed that they were limited, $45 \%$ subjects viewed them reasonable. The results here demonstrated that the number of College English Follow-up Elective Courses was not plentiful enough to meet students' need. The number of College English Follow-up Elective Courses in future should be increased.

Regarding the content of the textbook, 37\% subjects considered it moderate, $31 \%$ subjects considered it difficult, and $24 \%$ subjects considered it easy. The results suggested that the content of the textbook were not good enough to meet students' need. The difficult degree of the textbook content in future is supposed to meet students' need.

About the function of College English Follow-up Elective Courses, $30 \%$ subjects thought that it met their interests for English learning, 24\% subjects thought that it would help them to understand their major courses textbooks which are English edition. 17\% subjects thought that it expanded their knowledge. 29\% subjects thought that College English Follow-up Elective Courses was useless.
These results showed that the function of College English Follow-up Elective Courses met most of students' need. Teachers or researchers might further probe students' special requirement for College English Follow-up Elective Courses in future.

Concerning teaching methods of College English Followup Elective Courses, $30 \%$ subjects preferred interactive classroom for the course, $32 \%$ subjects preferred practicing in real situation, $38 \%$ subjects preferred the combination of teacher' transmission and exercises. $47 \%$ subjects preferred the collaborative teaching, which several teachers lecture a couple of chapters of the textbook for a course respectively, to one teacher for a course. These results suggested that students preferred different teaching methods. Teachers are supposed to adopt proper teaching methods according to the type of College English Follow-up Elective Courses in further.

With regard to assessment, $62 \%$ subjects liked to take a final examination, $38 \%$ subjects preferred to hand in term paper. All of them were not accustomed to the formative assessment. These results demonstrated that students preferred different assessment, and that they were not used to new assessment. Teachers or researchers might further probe advantages and disadvantages of different assessment for College English Follow-up Elective Courses in future.

As regards learning effect, $57 \%$ subjects thought that it was good, $33 \%$ subjects thought that it was moderate, and $10 \%$ subjects thought that it was bad. These results showed that the learning effect of College English Follow-up Elective Courses were good. Teachers or researchers might further probe why some students' learning effect were bad.

About subjects' suggestion for College English Followup Elective Courses, $25 \%$ subjects suggested using textbooks with more topics, $25 \%$ subjects suggested using textbooks with latest information in the world; $29 \%$ subjects suggested that the size of class be less than 35 students, $41 \%$ subjects suggested that the size of class be less than 40 students, $14 \%$ subjects suggested that the size of class be less than 45 students; $49 \%$ subjects suggested improving students' attendance to class by taking effective measures. These results showed that subjects' suggestions for College English Follow-up Elective Courses were mainly about the content of the textbooks, class size and students' attendance to class, which provided much food for thought concerning College English Follow-up Elective Courses teaching and learning.

\section{CONCLUSION}

\section{A. Main Findings}

Based on the results of the questionnaire, the major findings coming from the present study can be summarized as follows:

Firstly, the type and number of College English Followup Elective Courses were not sufficient enough to meet students' need.

Secondly, the content of the textbook were not abundant and new enough to meet students' learning need. 
Thirdly, the function of College English Follow-up Elective Courses met most of subjects' need.

Fourthly, subjects preferred different teaching methods in College English Follow-up Elective Courses instruction.

Fifthly, subjects preferred different assessment, and they were not used to formative assessment.

Sixthly, most subjects agreed that the learning effect of College English Follow-up Elective Courses was good.

Lastly, subjects preferred smaller class size than it was, and hoped improving their attendance to class.

\section{B. Suggestions on College English Follow-up Elective Courses}

Based on the findings of the study, here are some suggestions on College English Follow-up Elective Courses:

Firstly, to increase the type and number of College English Follow-up Elective Courses in future according to students' learning need.

Secondly, teacher might choose newly published textbooks and supplement the latest information of the course in their lectures according to students' English learning need.

Thirdly, Teachers are supposed to adopt proper teaching methods according to the type of College English Follow-up Elective Courses and students' special requirement for it.

Fourthly, Teachers and researchers might further probe advantages and disadvantages of different assessment for College English Follow-up Elective Courses in future, and guide students to adapt to formative assessment.

Lastly, based on the investigation of the specific courses, to decrease the class size and take effective measures to insure students' attendance to class.

\section{Limitations and Suggestions on Future Research}

However, the present study unavoidably included some limitations, like small sample size, lacking interview etc.. And here are some suggestions for future research. Firstly, larger sample size is indispensable. Secondly, a survey with interview and class observation could get more fruitful findings.

\section{REFERENCES}

[1] Gaodeng jiaoyusi, College English Curriculum Requirements, Shanghai, China: Shanghai foreign language education press, 2007, pp.31.

[2] Ji-gang, Cai, "English for academic purposes and quality foreign language education," Computer-Assisted Foreign Language Education in China, Vol.157, No.3, pp.3-6, May, 2014.

[3] Wu-lin Ma, "On content designing of College English Follow-up Elective Courses I: English for academic purpose," Foreign Language Research, Vol.129, No.5, pp.15-21, May, 2011.

[4] Shou-ren Wang, Hai-xiao Wang, "Analysis of Social Needs for College English," Foreign Languages in China, Vol.43, No.5, pp.4-11, Sep. 2011.
[5] Xue-qing Fu, "Reflections on the curriculum development of College English Follow-up Elective Courses based on "demand analysis," Computer-Assisted Foreign Language Education in China, Vol.156, No.3, pp.74-78, Mar. 2014.

[6] Bin Chen, "An experimental study on cultivating college non-English majors' abilities to express Chinese culture in English through College English teaching," in proceedings of the 2015 international conference on education research and reform (ERR 2015), Book series: Advances in Social and Behavioral Sciences, Vol.8, Xiao-fang Zhu Eds., Foresque Residence, Singapore: Singapore Management and Sports Science Institute, PTE.LTD, 2015, pp.8-14.

[7] Bin Chen, "A survey on cultivating college non-English majors' abilities to express Chinese culture in English through College English teaching," in proceedings of the 2015 international conference on arts, design and contemporary education (ICADCE 2015), Book series: Advances in Social Science Education and Humanities Research, Vol.23, P. Perry et al. Eds., Paris: Atlantis Press, 2015, pp.710-713. 